\title{
Town resource cluster analysis - understanding and quantifying your operation's social and economic linkages at local, regional and state levels
}

\author{
S Coakes Umwelt Australia, Australia \\ K Lamb Umwelt Australia, Australia
}

\begin{abstract}
This paper demonstrates an applied approach to assessing the socio-economic impacts of mine closure using the application of Town Resource Cluster (TRC) analysis; a methodology developed in Australia for application within a natural resource management and development planning context. The methodology provides opportunity to examine the linkages between a resource operation and social systems, and affords quantification of economic and social contribution at local, regional and state levels to guide operational planning and decision-making at various phases of an operation's lifecycle.
\end{abstract}

In the context of mine closure planning, TRC analysis delineates the social and economic associations between a mine and its local and regional communities based on a number of factors, including: employee (and family) place of residence; use of services; annual household expenditure; employee involvement; and participation in local community life. Data relating to supplier linkages can also be demonstrated and quantified.

This paper illustrates that by using TRC analysis, an operational site can obtain an understanding of both the positive contribution that its operation is presently making, as well as identifying and quantifying the potential impacts on local towns and communities as the mine closure process commences. Such a process ensures no surprises and affords the effective management of change at local and regional levels.

The technique is presented further through discussion of a number of case studies where it has been practically applied.

\section{Introduction}

The closure of any mining operation brings with it a number of economic and social issues and risks. Assessing and predicting the likely positive and negative changes associated with closure and effectively integrating the socio-economic aspects of mine closure with other technical inputs remains an ongoing challenge. One of the rigorous approaches to assist in the quantification of socio-economic impacts in the mine closure process is that of Town Resource Cluster (TRC) analysis; a methodological framework originally developed in Australia for application within a resource management and planning context (Fenton et al. 2003). This framework has been applied at a regional planning scale and specifically across a number of resource management contexts, including: forestry (Fenton 1998, 1999a, 2000a; Coakes Consulting 2009; Natural Resources Commission 2010), mining (Fenton 1999b; Coakes Consulting 2002, 2013, 2014), water resources (Fenton 1999c, 2000b) and fisheries (Fenton \& Marshall 2000). Figure 1 illustrates the conceptual framework developed. 


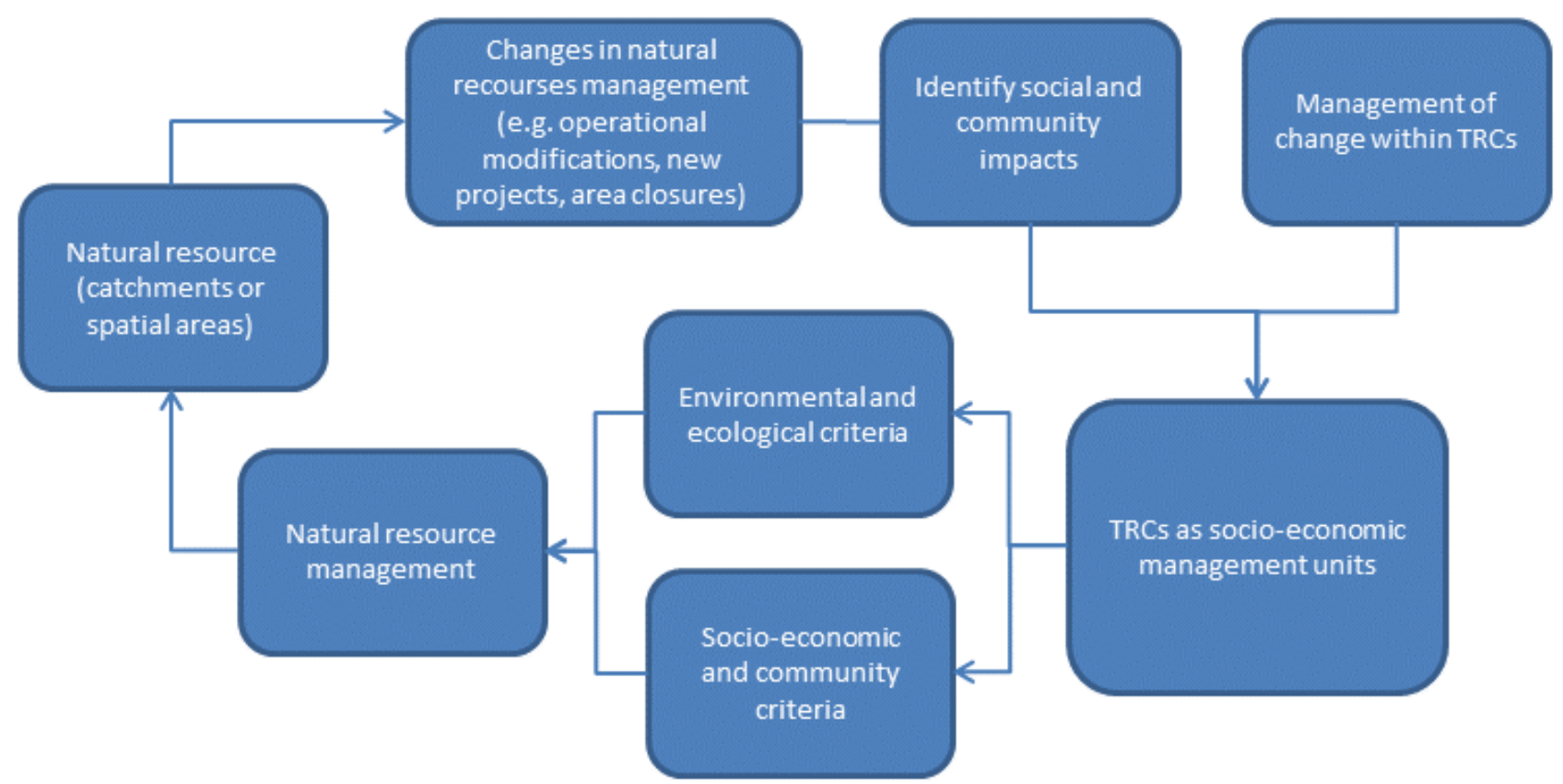

Figure 1 A model for the integration of social and environmental systems. Adapted from Fenton et al. (2003)

In simple terms, TRC analysis provides the opportunity to describe and examine the relationships and inter-dependencies between resource systems, the operations that utilise these resources and social and economic systems.

This paper discusses the application of a TRC approach within the mining sector, in particular, in the context of downscaling a mine's operations in preparation for closure.

\section{Identifying the linkages between an operation and its social and economic context}

During the life of a mine, there are a number of ways in which an operation and its community become associated, including through the actions of the company itself, its employees, contractors and suppliers. TRC analysis helps identify these social and economic associations between a mining operation and its local and regional communities based on a number of direct and indirect contributions. From a company or operation's direct actions, economic associations can include community contributions and social investment activities such as the provision of direct and indirect funding for capital infrastructure; partnership programmes and sponsorship of community events and initiatives; employment activities; and company expenditure. The linkages between an operation and its suppliers can also be demonstrated and quantified with these linkages being determined by the identification of the location(s) of the suppliers business(es); residential locations of supplier employees; the extent of supplier business dependency on the operation; and the businesses own expenditure patterns.

From an employee or contractor perspective, these associations include the places or localities where employees and/or contractors and their families reside; their use of local and regional infrastructure and services, such as education and health; household expenditure patterns; and extent of involvement in local community life.

\section{The TRC approach}

Confirming the above linkages and collecting the required information to support TRC are typically met through collection of primary data direct from relevant stakeholders, complemented by analysis of relevant secondary data sources. The following sections outline the two main phases involved in undertaking TRC 
analysis. These phases are discussed in the context of a mine closure planning project case study for a mining operation located in the western coalfields of New South Wales, Australia. The project referred to is owned and managed by a large resource company and is considered one of the oldest operations in the western coalfields region.

At the time of the project, a mine closure plan was being prepared by the operation to meet company policy, which required that a plan be developed that addressed all economic, environmental and social factors associated with closure. Closure was predicted to occur within a five-year period of the work being undertaken. A socio-economic impact assessment was therefore undertaken to support the preparation of the mine closure plan. The assessment programme employed a range of mechanisms to identify potential closure impacts and obtain the views and perceptions of key stakeholders.

\subsection{Understanding the linkages and associations}

The first step of TRC analysis is the collection and review of existing company data from human resource and operational business functions. Depending upon the record-keeping activities of the company, such data will include:

- Employee and supplier data, i.e. townships of residence or residential postcodes.

- Operating costs.

- Company spend contribution to community groups and organisations.

- Environmental initiatives.

- Environmental monitoring programmes.

- Number of trainees apprentices.

The collection and analysis of this information provides an initial picture of the operation's activities and also a means for validation of employee and supplier data collected during the survey activities outlined in Table 1.

Following the initial collection and analysis of the above company information, primary data are then sourced directly from employees, contractors and company suppliers. Examples of information collected by the participant group are provided in Table 1. 
Table 1 Data requirements to support TRC analysis (Fenton et al. 2003)

\begin{tabular}{ll}
\hline Stakeholder group & Examples of information \\
\hline Employees/contractors & Location of residence \\
& Household composition \\
\hline Status and length of employment & Personal and household income \\
\hline Annual expenditure patterns - value and by location \\
\hline $\begin{array}{l}\text { Participation in community groups and organisations, e.g. volunteering and } \\
\text { donations }\end{array}$ \\
\hline $\begin{array}{l}\text { Long term residential expectations post-closure } \\
\text { Use of local services, e.g. attendance of children at local schools, use of local } \\
\text { health services }\end{array}$ \\
\hline $\begin{array}{l}\text { Number of employers and employment status, e.g. casual, full-time } \\
\text { Employee location of residence }\end{array}$ \\
\hline Extent of dependence on mining operation \\
\hline Existing contracts with mining operation (value, nature) \\
\hline $\begin{array}{l}\text { Percentage of the annual business income spent on goods and services } \\
\text { Location of company purchases goods and services }\end{array}$ \\
\hline
\end{tabular}

In a TRC framework, primary data are largely sourced through survey methods, such as:

- Online surveys - utilising survey platforms such as Survey Monkey.

- Hard copy surveys mailed to stakeholders with return paid envelopes enclosed.

- Personal distribution of hard copies through existing business mechanisms, for example shift changes, tool box talks and workplace meetings.

- Directly through personal telephone interviews.

Collection of data through existing business mechanisms is often the most successful. Given personal interaction with participants, response rates are usually higher and a good sample can then be used to extrapolate the collected data to the broader workforce population. Supplier surveys are usually successfully implemented via online surveys through the provision of business listings, so that the survey can be completed directly online.

The collection of primary survey data, combined with secondary data obtained via the operation itself, thus provides a very comprehensive picture of contribution - both economic and social at local community and regional levels.

Aside from the collection of data to directly facilitate the TRC in the context of mine closure, the distribution of surveys and engagement with relevant stakeholders can also provide the opportunity to collect other information that supports mine closure planning and associated impact assessment activities, such as:

- Employee/contractor education and intentions post mine closure.

- Community issues and concerns in relation to closure. 
- Possible strategies and solutions for addressing the issues raised that take into account community needs and aspirations.

- Suggestions for potential post-closure land use options for further assessment and consideration.

- Information requirements and recommended timing and mechanisms for information delivery as closure approaches.

In relation to the closure case study undertaken, some of the key demographic, socio-economic and employment characteristics of employees and contractors associated with the mining operation are discussed. The information provided is based on the outcomes of an employee and contractor survey completed during designated workforce training sessions at the end of every shift, over a 24 hour period. As the entire workforce did not respond to the survey, data and information provided by the human resource department of the company has also been used to assist in predicting impacts associated with operational closure.

\subsubsection{Workforce profiling}

Examples of some of the key characteristics of the operational workforce that was collected to form an employee profile include the following:

- Age.

- Employment role.

- Length of time working for the operation.

- Did you move to the area to take up a position with the operation?

- Do you have another job in addition to your position at the operation?

- Do you have another job in addition to your position at the operation? What sector?

- Highest level of school education and additional qualifications.

- Home ownership.

- Length of time in town or suburb of residence.

- Household size.

- Age of dependent children in the same household.

As the list above indicates, the approach provides some solid information about the nature of the workforce and their current position. For instance, we know that the workforce is older, with the majority (58.6\%) aged over 45 years and is quite established, with around $43 \%$ of workers having worked at the operation for 16 years or more. There are also a proportion of employees $(49 \%)$ who are newer to the operation, having been in their respective roles for less than five years. The majority of the workforce respondents indicated that they were employed as production employees (43.2\%), followed by tradespersons (28.8\%) and management/supervisory positions (15.8\%). Interestingly, for those that reported having other jobs in addition to their current position, a large proportion of the samples were also employed as community and personal service workers. The Australian Bureau of Statistics (ABS) classifies community and personal service workers as those who provide the community with personal services such as gardening, photography, cleaning and maintenance, home repairs etc. As the provision of these services do not typically require an engagement of full-time working hours, it is not surprising that among those employees who have additional jobs in conjunction to their primary one at the colliery, most tend to be involved in these types of personal service roles.

Most employees had completed Year 10 or equivalent at school, with around 19\% completing Year 12 or equivalent. Many of these employees/contractors had also completed further education and trade-related 
training after having left school (76\% of respondents), with the most common course types being trade/TAFE and First Aid certificates. These qualifications complement roles which are typical of the mining industry.

The majority of respondents reported that there was more than one person living in their household. This suggests that most either lived with their partner/spouse, or had dependent children/dependent elderly adults living in the same residence. Some also indicated living in group housing.

The survey also asked about the type of work undertaken by the respondents' spouse/partner. The majority were identified as homemakers $(25 \%)$, followed by community and personal service workers (24\%). Housing tenure type was also identified.

Data from company human resources records and survey data also indicates that mine employees working for the operation reside in a number of townships across the local government area (LGA) and further afield. As shown in Figures 2 and 3, the human resource and survey data are comparable, with the townships of Lithgow, Portland and Wallerawang being the main townships of residence for employees/contractors.

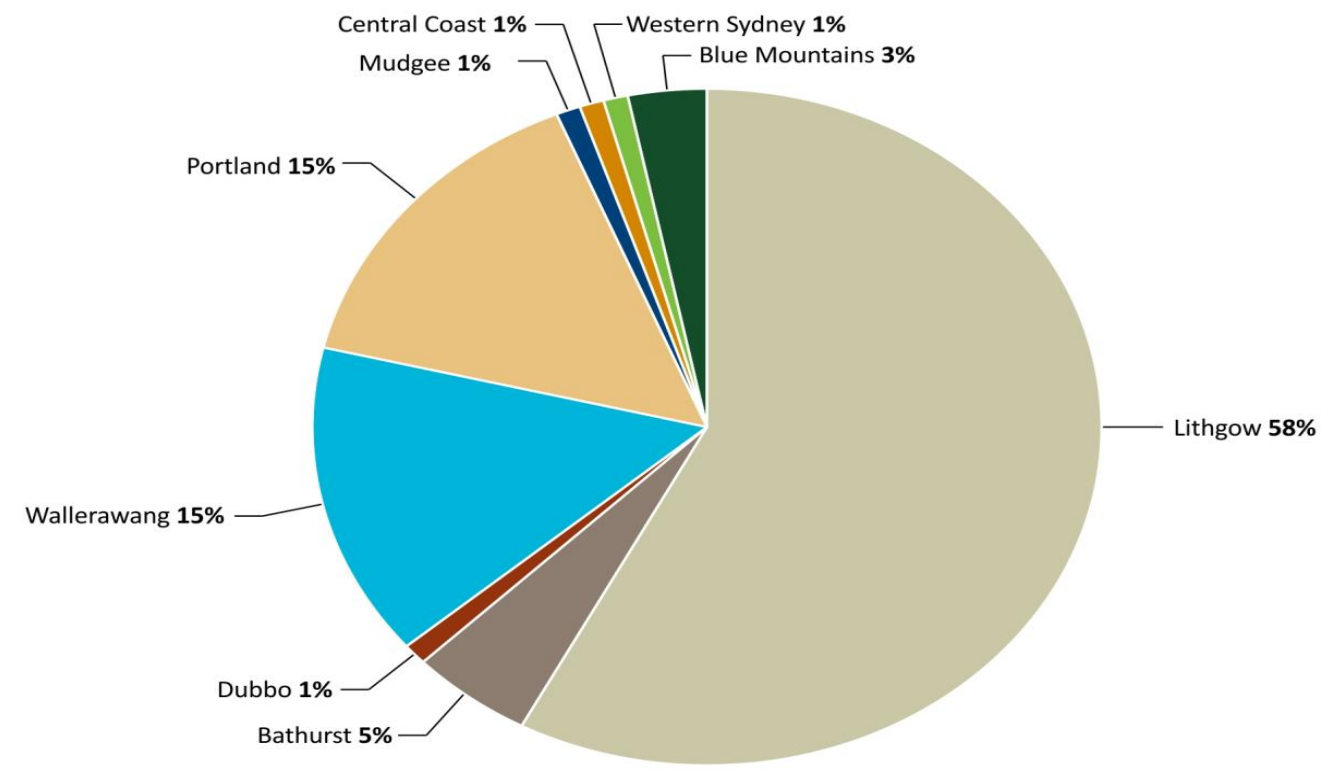

Figure 2 Residential location of employees overall

Where is your primary residence? (town/locality)

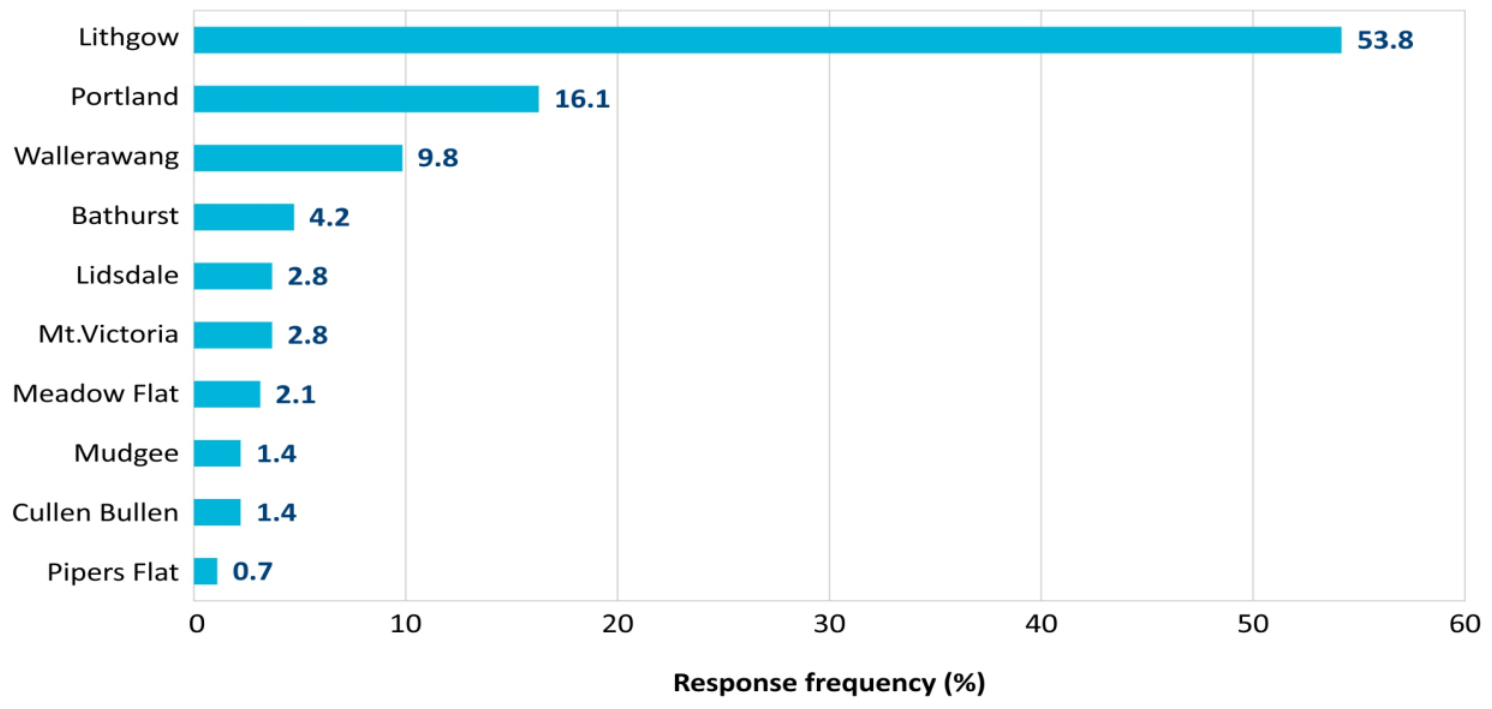

Figure 3 Place of primary residence (employee and contractor survey) 
The survey also indicated that around $15 \%$ of operation employees also volunteer their time in local community groups. Of those that do participate in voluntary services, the majority serve with the bush and local fire brigades. The workforce survey data has also enabled us to determine where these families utilise services across the region. Figures 4(a) to 4(d) highlight key schools attended by family members of employees, as well as their use of childcare and health services.

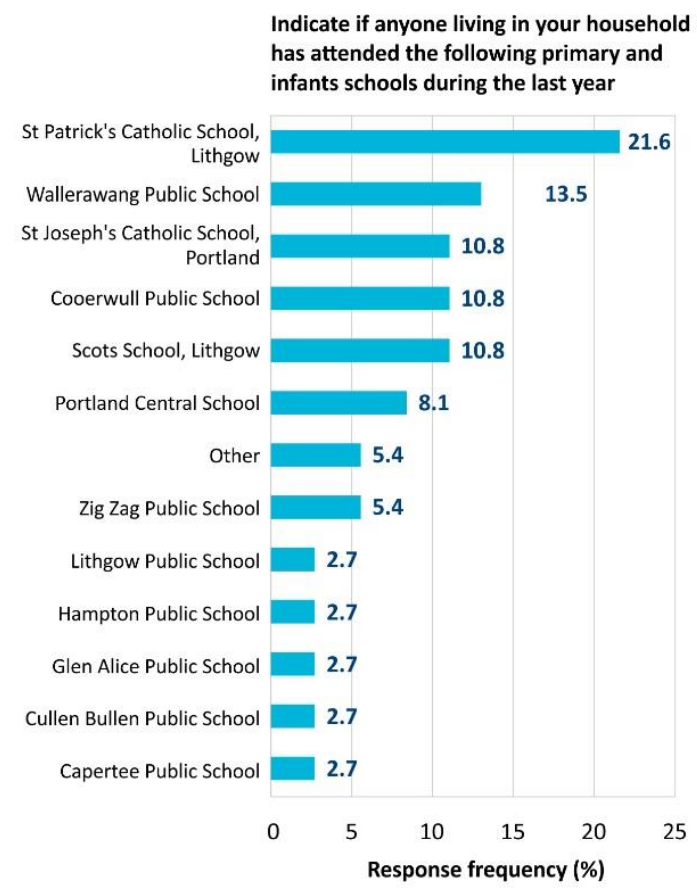

(a)

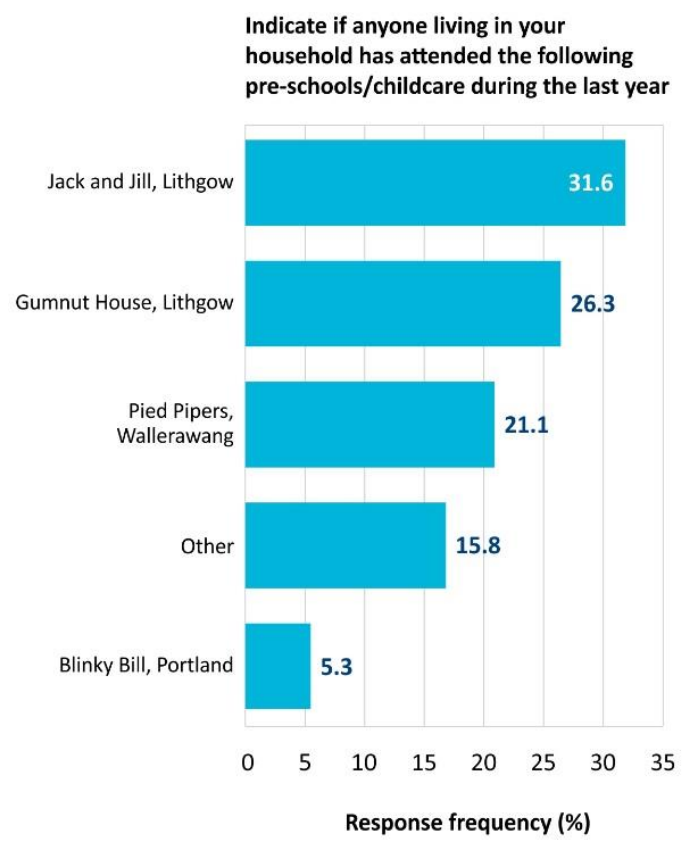

(c)

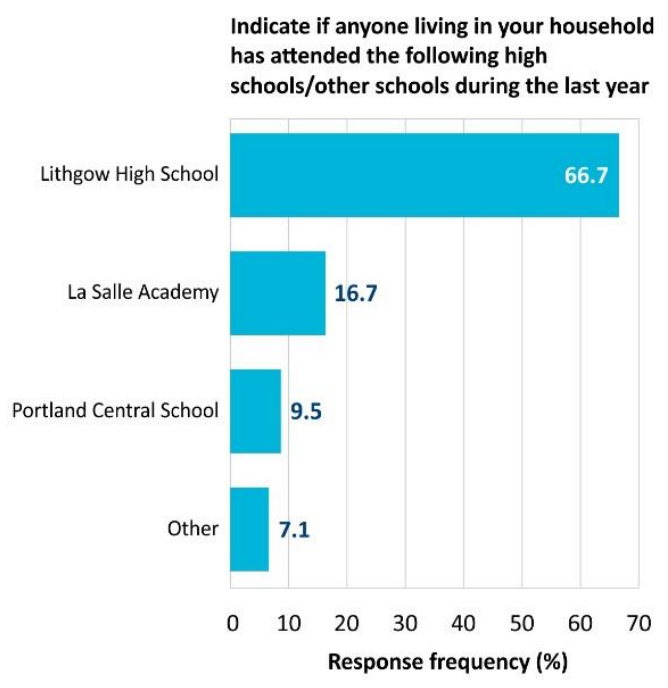

(b)

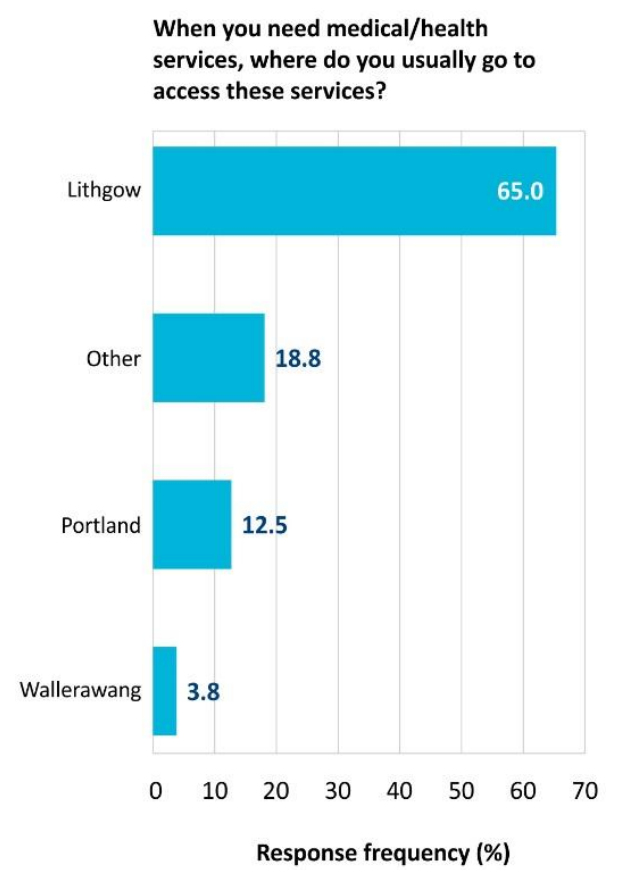

(d)

Figure 4 Employee and contractor survey: (a) primary and infant schools attended; (b) high schools attended; (c) pre-schools attended; and (d) places where medical/health services are accessed

Economic data relating to average employee wage was also collected to assist in the prediction of economic impacts in Phase 2. 


\subsection{Assessing the likely impacts of closure}

Data collected through the application of TRC are analysed and also considered spatially to demonstrate the direct and indirect flow-on effects of the presence of a particular operation in an area.

The primary objective of TRC, in the context of mine closure, is to identify those towns with a direct or indirect dependency on an operation and then allow for further spatial analysis to focus on the specific communities that are likely be affected by its closure, rather than those simply in proximity to the mining operation.

Towns which have dependencies on an operation are identified on the basis of the information collected via the data collection activities to develop an understanding of the social and economic contributions the operation makes to the surrounding communities and, consequently, the likely impacts of operational closure. Such changes or impacts may include:

- Impacts on local populations (as a result of changing workforce numbers) and sense of community.

- Impacts on local/regional infrastructure and services, e.g. decline in school numbers.

- Economic impacts.

Each of these impact categories is further discussed below in relation to the closure case study.

\subsubsection{Impacts on local population}

Changes in population, either increases or decreases, can bring about a range of social impacts at an individual, family and community level. Such changes may be associated with the workforces (construction and operation) associated with large scale development projects, but also the closure or cessation of an existing operation. The magnitude of impacts associated with a mine's closure on surrounding communities will be dependent on a number of factors including but not limited to:

- The number of mine employees and their respective family sizes.

- The existing involvement of mine employees and their families in community activities, for example, volunteering.

- Their intentions with respect to relocation following mine closure.

For example, for the 102 employees residing in Lithgow, assuming that they each have a family size of 2.4 people, then the total number of people associated with the operation in the township of Lithgow is 245 people, and the number associated with Portland and Wallerawang is 62 people for each township (Table 2). 
Table 2 Residential location of operational employees

\begin{tabular}{lccc}
\hline Residential location & $\begin{array}{c}\text { Number of } \\
\text { employees }\end{array}$ & $\begin{array}{c}\text { \% of employees } \\
\text { Lithgow }\end{array}$ & $\begin{array}{c}\text { Family impacts } \\
\text { (employees) }\end{array}$ \\
\hline Wallerawang & 26 & 58.6 & 245 \\
\hline Portland & 26 & 14.9 & 62 \\
\hline Bathurst & 9 & 14.9 & 62 \\
\hline Blue Mountains & 5 & 5.2 & 22 \\
\hline West Sydney & 2 & 2.9 & 12 \\
\hline Mudgee & 2 & 1.1 & 5 \\
\hline Central Coast & 1 & 1.1 & 5 \\
\hline Dubbo & 1 & 0.6 & 2 \\
\hline Total & 174 & 0.6 & 2 \\
\hline
\end{tabular}

Assuming that all employees and their family members in these localities are of usual working age, i.e. under the age of 65 years; and utilising the age distribution of the general population under the age of 65 years in these localities in the ABS (2006) census data, the following population changes are predicted across the three main townships in which employees reside (Table 3). As the table shows, closure of the operation would result in 245 people being affected in Lithgow; $42 \%$ of those are aged between 40 and 64 years and a further $21 \%$ aged 25 to 39 years.

Table 3 Predicted population impacts for Lithgow, Wallerawang and Portland suburbs

\begin{tabular}{lcccccc}
\hline \multirow{2}{*}{$\begin{array}{l}\text { Age } \\
\text { ranges }\end{array}$} & \multicolumn{2}{c}{ Lithgow township } & \multicolumn{2}{c}{ Wallerawang suburb } & \multicolumn{2}{c}{ Portland suburb } \\
\hline $0-4$ & ABS & People & $\%$ & People & $\%$ & People \\
\hline $5-11$ & 6.6 & 16 & 8.7 & 5 & 7.1 & 4 \\
\hline $13-17$ & 11.1 & 27 & 12.6 & 8 & 11.2 & 7 \\
\hline $18-24$ & 7.8 & 19 & 8.6 & 5 & 9.0 & 6 \\
\hline $25-39$ & 11.4 & 28 & 8.1 & 5 & 7.2 & 4 \\
\hline $40-49$ & 20.7 & 51 & 22.8 & 14 & 20.1 & 12 \\
\hline $50-64$ & 17.2 & 42 & 17.7 & 11 & 17.7 & 11 \\
\hline Total & 25.2 & 62 & 21.6 & 13 & 27.8 & 17 \\
\hline
\end{tabular}

When asked what their preferences were in the event of mine closure (e.g. retire, seek alternative employment), a substantial proportion of survey respondents (37\%) indicated that they would most likely seek alternative employment in a similar industry in the area. Approximately $25 \%$ of respondents also suggested that they would retire. This finding is not surprising given that a large sample of the employees surveyed were in the older workforce ages of 45 years and over.

The outflux of families in an area also may have an impact on the sense of community within the localities in which employees reside. As previously noted, a proportion of the operational workforce volunteer their time in local community groups and organisations and consequently the loss of population may result in 
reduced participation and disruption to local networks, which may be particularly felt in communities of smaller population sizes.

\subsubsection{Impacts on service sectors}

Another potential impact resulting from the closure of a mine relates to impacts on the viability or sustainability of local social infrastructure, such as schools and health facilities, should there be a substantial decrease in the population and a decrease in people utilising or requiring those services. Consequently, as part of the closure planning case study, impacts on service delivery associated with any population change were also considered.

In our project example, it was considered that there would be limited impacts on the viability of local schools resulting from closure of the operation. This is due to a number of factors, namely:

- That the operational workforce is an older one, with $46.3 \%$ of the survey respondents indicating that they did not have any dependents living at home.

- The majority of the workforce indicated their intention to stay in the local area.

- The wide range of schools attended by the children of workforce members, i.e. mine workforce children are distributed over a wide range of schools.

The exception was those schools located in the smaller communities which already have low student and teacher numbers. This is particularly the case should those workforce families decide to leave the local area. While the number of workforce employees utilising these local schools was quite low, the removal of even one student can sometimes have a large impact on a school's viability.

As part of the survey, the occupation of employees' partners/spouses was also determined, with the majority of spouses or partners identified as being homemakers $(25 \%)$, followed by community and personal service workers (24\%) and professionals (17.3\%). Depending on the industries of employment in which these spouse/partner are employed, and identification of shortages across particular vocational areas, there may be additional flow-on impacts to the community experienced, should these workforce families decide to leave the local area.

\subsubsection{Economic impacts}

Data collected utilising a TRC approach can also be used to predict the economic impacts of closure at a local and regional level. Workforce survey analysis has been used to determine the economic contribution of the colliery's workforce at the local level, and to develop a profile of the existing operation and its employees in the region.

The economic impact of closing down a mine is the reverse side of opening one up, and the same principles of economic analysis apply. That is, when a mine is proposed for an area, part of the impact will be the mining jobs created in the area and the earnings that are to be paid to local businesses. The fact that some of the new project's employees may already live in the area is a refinement that is unhelpful. This view is taken because the person already in the area will be either new to the workforce or is transferring from another job. Either way, their employment represents a net gain for the local area.

The relevant comparator is the situation that would prevail if the mine were not to exist. If a mine were to close its operations, the impact for individuals might be minimised if they gain alternative employment and the impact on the local businesses might be reduced if the redundant employees retire in the area. However, the eventuality of these changes taking place has not been considered in this analysis. The central question addressed via the following economic analysis is the net impact of the change occurring at the mining operation.

The economic impact assessment has therefore involved multiplier analysis modelling to assess the flow-on effects on income, investment and employment of the colliery on distant economies. In assessing the economic impact of the closure of a mine, an assessment is made of both the direct and indirect effects. 
The direct impacts are the expenditures by the mine operators on materials, employees, fuel and other operating and ongoing expenses. The indirect effects are generated by what the recipients of these expenditures do with their earnings. The indirect effects have a flow-on effect, with successive waves of earnings and then expenditures occurring.

The multipliers used in this section are estimates of the impacts in terms of output and employment. The output multipliers represent the reduced needs for goods and services that were previously purchased throughout the economy, and are a sum of the materials and services needed by the project, their flow-on requirements, and the goods that were previously purchased with the wages and salaries paid by the coal mine. The employment multiplier is similar and shows the total knock-on impact of mine closure for employment more widely.

\subsubsection{Employee expenditure}

Those working at the operation will have an economic impact through their weekly expenditures. With respect to household expenditure activities, TRC analysis identifies the median income brackets of the survey respondents and compares these to household income quintiles as provided and published annually by the ABS Household Expenditure Survey on their website (ABS n.d.). By identifying the quintile that most closely aligns with respondents stated incomes, it is possible to identify the proportion of income that is spent, on average, by those that fall within a particular income quintile. For example, based on the average annual incomes of the workforce which has been identified as approximately AUD 100,000, average weekly household expenditure of the workforce is estimated to be AUD 1,052 per week. This number is multiplied by the number of employees and by the number of weeks in the year to get a total of household expenditure for employees of the mine. These figures suggest a household expenditure figure representing some 55 per cent of household income which would be expected for salary earners in this income bracket.

The employee and contractor survey also asked participants to identify the townships from where they typically purchase items for their household, such as example grocery items, clothing, petrol and other goods and also to identify the percentage or proportion of household expenditure that was undertaken at each location.

Utilising the information above, we can determine the extent and location of expenditure across the employee workforce. In our current case study, based on the responses received, expenditure on household items typically occurs within the township of Lithgow, followed by Bathurst (Figure 5).

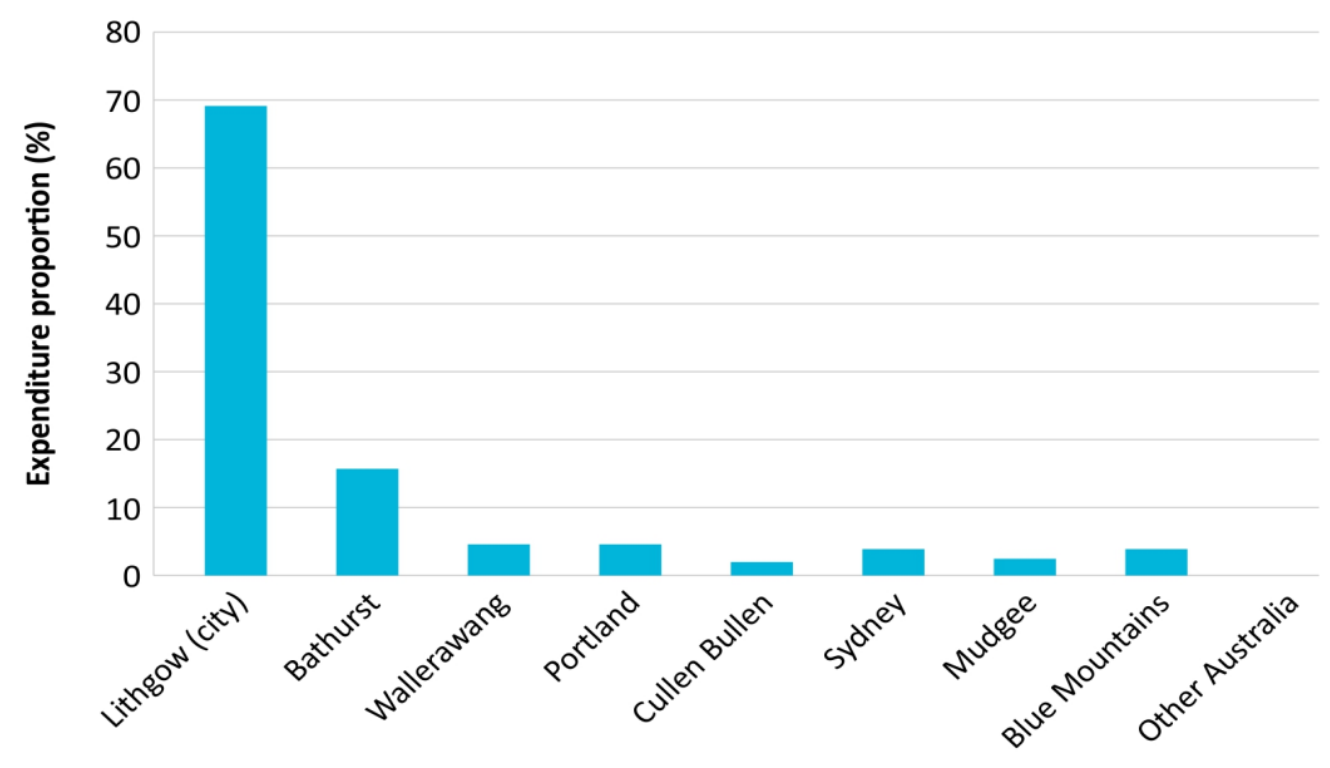

Location of household expenditure

Figure 5 Location of workforce employee expenditure 
This is not surprising given that these are the two largest regional towns close to the operation and where the workforce resides. While individuals will usually spend most of their household expenditure in their town of residence, their expenditure will be distributed more widely to other towns and regional centres.

Salaries and contractor labour fees cost the operation approximately an average a total of AUD 26.780 million a year. Of this total, some AUD 11.269 million is estimated to be spent each year as household expenditure. As the following table indicates, this expenditure is spread across the region; with the majority of it (73 per cent) being spent in the Lithgow LGA (Table 4).

Table 4 Annual economic impacts of workforce expenditures

\begin{tabular}{lcc}
\hline Area & Average annual employee and contactor spend (AUD millions) \\
\cline { 2 - 3 } & Direct & Multiplied \\
\hline Lithgow City & 7.640 & 11.842 \\
\hline Wallerawang & 0.462 & 0.716 \\
\hline Cullen Bullen & 0.101 & 0.157 \\
\hline Portland & 0.349 & 0.541 \\
\hline Total Lithgow LGA & $\mathbf{8 . 5 5 2}$ & $\mathbf{1 3 . 2 5 6}$ \\
\hline Bathurst & 1.679 & 2.602 \\
\hline Mudgee & 0.259 & 0.401 \\
\hline Blue Mountains & 0.372 & 0.577 \\
\hline Sydney & 0.383 & 0.854 \\
\hline Total NSW & $\mathbf{1 1 . 2 4 5}$ & $\mathbf{2 5 . 0 7 6}$ \\
\hline Other Australia & 0.023 & 0.051 \\
\hline Total Australia & $\mathbf{1 1 . 2 6 8}$ & $\mathbf{2 5 . 1 2 8}$ \\
\hline Imported & & \\
\hline Overall total & $\mathbf{1 1 . 2 6 8}$ & $\mathbf{2 5 . 1 2 8}$ \\
\hline
\end{tabular}

NB. Note that the multiplier impacts include the initial direct impacts of the project.

While most of the direct expenditure is made within the Lithgow LGA, the multiplier effects are equally spread between the LGA and the rest of the NSW economy, with every dollar that is spent by households having a multiplier effect through the local and more distant economies. This means that the flow-on impacts of expenditures in communities, such as the townships of Lithgow and Wallerawang, have a multiplier impact in the local town, as well as an impact on other towns within the wider region. The impact on the total state economy is greater than the sum of the impacts on the individual towns within the immediate region of the mine. Overall, based on the outcomes of multiplier analysis represented above, household expenditure of the operations workforce currently makes a considerable contribution to the local and state economies.

\subsubsection{Spending on materials and equipment}

A second significant and current economic contribution that the operation makes on the local economies is from the company's expenditure on materials and equipment, i.e. everything other than expenditure on labour, referred to in this discussion as 'materials' to cover items including equipment and materials for site preparation, conveyors and other earthmoving equipment, contractors, mine site accommodation, 
transport and marketing, and the ongoing use of materials such as repairs and replacement parts, fuel and explosives.

The total annual expenditure on materials is estimated at AUD 73 million, of which some seven per cent is expended in the Lithgow LGA. The bulk of expenditure is made within the economy of NSW with some 90 per cent being expended within the state. A proportion of expenditure is also on imported goods.

Annual expenditure on operations and materials is of less significance to the Lithgow area than the annual household expenditure by employees. Also the multipliers for household expenditure are greater, so the overall impact of the operation on the local economy is more pronounced.

While the local area multipliers for expenditure on operations and materials are smaller than for employee expenditure, the state-wide multipliers for this expenditure are greater than for the local area. The expenditure on materials by the operation is significant at the state level, both in terms of their direct impact and multiplier impact.

This analysis indicates that the expenditure on materials, services and equipment, plus the expenditure by the households of mine employees, directly injects AUD 13 million into the economy of the Lithgow LGA and AUD 77 million into the NSW economy per annum. When account is taken of the economic multipliers, the mine is creating a total demand for product from the Lithgow LGA economy of AUD 19 million a year.

The impact at the level of the state economy is large. The expenditures from the mine generate a demand in output from the state economy of some AUD 141 million a year. The discontinuation of these demands, with closure of the mine, will have a noticeable impact on the state economy and a particularly significant impact on those businesses which are most aligned to provide services to the mining industry.

\subsubsection{Jobs created by the project}

The operation employs an average of 174 employees and 32 contractors and, consequently, there is a multiplier effect also on jobs. The operation itself is employing some 206 persons, but when taking multipliers into account, it is generating a further 515 jobs throughout the NSW economy. In the local area, as well as the 185 persons employed locally in the Lithgow LGA by the mine, there are an estimated further 228 jobs created in the Lithgow LGA, giving a total of 413 jobs.

Like the multiplier effects of expenditure, the job multipliers are larger for more widely defined regions. So while the operation directly employs 21 persons outside of the Lithgow LGA, it generates, through multiplier effects, a total of 308 jobs across the remainder of NSW.

\subsubsection{Community contributions}

The operation also supports the local community through its community contributions programme. According to company records, community contributions for the $2007 / 08$ financial year were estimated to total AUD 19,500, with expenditure planned for distribution across a number of community sectors.

\section{Conclusion}

This paper has illustrated, through a relevant closure planning case study, the application of TRC analysis in better understanding the social and economic impacts of change at a local and regional level. As the case study illustrates, the flow-on effects of mine closure from a socio-economic perspective result in many different types of impact that are often far reaching, extending further than the immediate community in which an operation is based.

TRC provides a means of better understanding potential impacts and changes at a local, regional and even state levels, enabling both companies and communities to better adjust to change. A further key advantage of the approach in a closure planning context is that the method also affords involvement of key stakeholders in the process. Through participation in the survey methods, key stakeholders are provided 
with a voice and input to the change process itself, which may facilitate a smoother and more robust transition at both an individual and community level.

As highlighted at the beginning of the paper, while valuable in the closure planning phase of an operation's lifecycle, the TRC method is not limited to just closure planning, it has been used extensively in decision-making relating to project development and/or modification, as well as in identifying impacts of changes in resource use as a result of policy initiatives e.g. forestry, fisheries, and viticulture.

\section{Acknowledgement}

The authors thank relevant operational and mine site personnel for allowing us to report on the data contained within and present within the context of this paper. We also thank the reviewers of this paper for their time and suggestions in the review process.

\section{References}

ABS (Australian Bureau of Statistics) 2006, Census of Population and Housing, www.abs.gov.au

ABS (Australian Bureau of Statistics) n.d., Annual Household Expenditure Survey, annual publication, www.abs.gov.au

Coakes Consulting 2002, Mount Arthur North Social Impact Assessment, Coal Operations Australia Pty Ltd, New South Wales, Australia.

Coakes Consulting 2009, Victoria's forestry communities: Adapting to change in the Forestry Industries, Department of Primary Industries, Victoria, Australia.

Coakes Consulting 2013, Social impact and opportunities assessment: Bulga Optimisation Project, report prepared for Xstrata Coal, Hunter Valley, New South Wales.

Coakes Consulting 2014, Social impact and opportunities assessment: Mount Owen Continued Operations Project, report prepared for Xstrata Coal, Hunter Valley, New South Wales.

Fenton, DM 1998, West Australian RFA: Forest Industry expenditure, catchment analysis and employee profiles, DPIE, Canberra.

Fenton, DM 1999a, Forest industry activity and linkages for the Gippsland CRA Region, Victoria, report prepared for the Social Assessment Unit, Agriculture, Forestry and Fisheries Australia (AFFA), Canberra.

Fenton, DM 1999b, Profiles of the mining industry and employees in Muswellbrook, New South Wales, Coal Operations Australia Pty Ltd, Muswellbrook, New South Wales.

Fenton, DM 1999c, TRC-Analysis for the Barron water allocation and management plan, Department of Natural Resources, Brisbane.

Fenton, DM 2000a, Social catchments and socio-demographic profiles for the South Brigalow CRA/RFA region (NSW), Department of Urban Affairs and Planning, Sydney.

Fenton, DM 2000b, TRC-Analysis for the Burnett water allocation and management plan, Department of Natural Resources, Brisbane.

Fenton, DM \& Marshall, N 2000, 'Social assessment of the commercial fishing industry in the Great Barrier Reef Marine Park: The application of TRC-Analysis in identifying primary and secondary resource catchments', in Proceedings of the International Coral Reef Symposium, Indonesia.

Fenton, DM, Coakes, S \& Marshall, N 2003, 'Vulnerability and Capacity Assessment', in H Becker \& F Vanclay (eds), The International Handbook of Social Impact Assessment, Conceptual and Methodological Advances, Edward Elgar Publishing, Cheltenham, UK.

Natural Resources Commission 2010, South western cypress state forest assessment (Section 4.6), Sydney. 